\title{
Calibration of hydrological models using TOPEX/Poseidon radar altimetry observations
}

\author{
WENCHAO SUN ${ }^{1,2}$, HAO SONG ${ }^{1,2}$, TAO CHENG ${ }^{1}$ \& JINGSHAN YU ${ }^{1}$ \\ 1 College of Water Sciences, Beijing Normal University, Xinjiekouwai Street 19, Beijing, 100875, China \\ 2 Joint Center for Global Change Studies, Beijing 100875, China \\ sunny@bnu.edu.cn
}

\begin{abstract}
This paper describes an approach for calibrating hydrological models using satellite radar altimetric observations of river water level at the basin outlet, aiming at providing a new direction for solving the calibration problem in ungauged basins where streamflow observations are unavailable. The methodology is illustrated by a case study in the Upper Mississippi basin. The water level data are derived from the TOPEX/Poseidon (T/P) satellite. The Generalized Likelihood Uncertainty Estimation (GLUE) method is employed for model calibration and uncertainty analysis. The Nash-Sutcliffe efficiency of averaged simulated streamflow by behavioural parameter sets is $64.50 \%$. And the uncertainty bounds of the ensemble simulation embrace about $65 \%$ of daily streamflow. These results indicate that the hydrological model has been calibrated effectively. At the same time, comparison with traditional calibration using streamflow data illustrates that the proposed method is only valuable for applications in ungauged basins.
\end{abstract}

Key words hydrological model; calibration; ungauged basin; radar altimetry; GLUE

\section{INTRODUCTION}

The possibility of estimating streamflow of large rivers from remote sensing of hydraulic variables has been well recognized in the last decades (Smith, 1997; Schumann et al., 2008). The methods using satellite information only are valuable for the case of ungauged basins. Sun et al. (2010) present a first trial in this new direction. Forgoing retrieval of the absolute amount of streamflow from space, they use satellite observations of river flow width at the basin outlet as a surrogate for streamflow data to calibrate a rainfall-runoff model. River flow width can be measured using many different types of imaging sensors. But, it is not effective to scale streamflow in rivers with vertical banks. In this paper, we present an approach to calibrate daily time-step rainfall-runoff models using only remotely-sensed river water levels at the basin outlet. This, provides a new orientation, different to the well-known regionalization approach, to overcome the obstacle to application of rainfall-runoff models in ungauged basins.

\section{METHODOLOGY}

The method is designed for basins without streamflow measurements, for which rainfall-runoff model cannot be calibrated directly. The intention is to use river water level observations for the river segment where the streamflow is computed as model output (usually considered as the basin outlet in rainfall-runoff modelling), derived from satellite radar altimeters, as surrogate calibration data. This demands model structure modification to make the model output variable match the observations (water level).

The first issue is to specify the relation between streamflow and water level ( $Q-H$ relation), in other words, how to convert streamflow simulated by the rainfall-runoff model into water level. In most ground gauging stations, continuous quantities of streamflow are computed from gauged water levels based on a rating curve taking the form (Ranz et al., 1982):

$$
Q=\mathrm{a} \times\left(H-H_{0}\right)^{b}
$$

where $Q$ is streamflow, $H$ is water level, $H_{0}$ is the elevation of the zero flow, $a$ and $b$ are two empirical parameters whose values reflect flow characteristics at the gauging station cross-section. The $a, b$ and $H_{0}$ are obtained from regression analysis between occasional velocity-area streamflow measurements and simultaneously observed water level. The inverse function of equation (1) is:

$$
H=\mathrm{c} Q^{f}+H_{0}
$$


where $Q, H$ and $H_{0}$ are the same as in equation (1), and $c$ and $f$ are two empirical parameters. The term $\left(H-H_{0}\right)$ can be considered as equivalent to flow depth $(D)$. So equation (2) can be treated as one variant of the at-a-station hydraulic geometry relation (Leopold and Maddock, 1953), which relates flow depth to streamflow using the power-law relation. If values of $c, f$ and $H_{0}$ for a crosssection are known, $H$ corresponding to certain value of $Q$ can be computed from equation (2). In this study, equation (2) will be used as the $Q-H$ relation that facilities modifying the rainfallrunoff model output.

The second issue is to change the model output. By coupling the rainfall-runoff model with equation (2), the output of the former (streamflow) serves as the input to the latter. Then the water level corresponding to the simulated streamflow is computed based on equation (2). The coupled modelling sequence can be treated as one single model to simulate river water level based on the rainfall-runoff relation of the target basin and the hydraulic relation at the basin outlet. The free parameters in this integrated model include rainfall-runoff model parameters, and the $c, f$, and $H_{0}$ in equation (2). The model calibration is the process in which these parameters are adjusted in order to match the simulated water levels to the satellite observations. Two points need to be emphasized here, which makes the method appealing for parameter estimation in ungauged basins. First, since the output is shifted to water level, streamflow becomes an internal variable of the model connecting the two components in the modelling sequence. Observed streamflow data are no longer required for the calibration. Second, different from the common approach of regression analysis using observed data, under the proposed calibration scheme, like the rainfall-runoff parameters, the $c, f$, and $H_{0}$ are fixed through the model tuning process as time invariants.

The third issue is the calibration algorithm. The calibration data are time discrete observations. The interval between two successive observations varies from several days to several months, depending on the satellite repeat cycle. Therefore, manual trial-and-error calibration that tries to make the model simulation closely resemble the "water level hydrograph" is not feasible in this situation. An automatic algorithm for locating the places in parameter space that optimize the pre-defined objective function which quantifies the model residual is required. The parameter estimates so obtained will be considered as capable ones that reflect the basin runoff generation process and the "river water level generation process" at the basin outlet properly. This new calibration scheme enables the application of the rainfall-runoff model in ungauged basins.

\section{THE UPPER MISSISSIPPI RIVER CASE STUDY}

\section{Description of the study area and satellite data}

The Upper Mississippi River in the USA originates from Lake Itasca in Minnesota state, flows roughly $2000 \mathrm{~km}$ to the confluence with the Ohio River at Cairo, Illinois state. Climate changes considerably within the basin; the mean average annual precipitation varies from about $600 \mathrm{~mm}$ in the north to $1220 \mathrm{~mm}$ in the south (Benke and Cushing, 2005). Rainfall-runoff modelling will be carried out for the upper stream area of the USGS gauging station at Clinton, Iowa state (no. $05420500,41^{\circ} 46^{\prime} 50^{\prime \prime} \mathrm{N}, 90^{\circ} 15^{\prime} 07^{\prime \prime} \mathrm{W}$ ), with a drainage area of $247600 \mathrm{~km}^{2}$. For the period 1998 2002, river water level observations of the Clinton region made by the T/P satellite were used. This data set was provided by the Géodésie Océanographie et Hydrologie Spatiales (GOHS) team at Laboratoire d'Etudes en Géophysique et Océanographie Spatiales (LEGOS) in France. It is freely available from LEGOS (http://www.legos.obs-mip.fr/en/soa/hydrologie /hydroweb/). For the repeat cycles when at least two $10 \mathrm{~Hz}$ observations are available within the observation window, the observations are geographically averaged to produce the mean water level. Then it is considered as the water level value. The standard deviation of the $10 \mathrm{~Hz}$ data in each repeat cycle is defined as the uncertainty associated with the mean level. For details about this product and data processing, please see Crétaux et al. (2011) and the information from LEGOS (www.legos.obsmip.fr/en/soa/hydrologie/hydroweb/General_Info.en.html). The uncertainties of all records are less than $35 \mathrm{~cm}$. 


\section{The rainfall-runoff model}

The HYMOD developed by Boyle (2001) was used in the case study. It is a parsimonious daily step model with a typical conceptual hydrological component. The runoff generation process is described by a simple rainfall excess model based on the probability-distributed principle (Moore, 1985). To account for the spatial heterogeneity of the meteorological condition in the target basin, HYMOD was revised to a semi-distributed version as in Sun et al. (2010). Based on the USGS hydrological unit map of accounting unit level, the upstream area of Clinton was divided into eight sub-basins as shown in Fig. 1. Considering the data scarcity in the basins where the proposed method is potentially applicable, two global datasets: the Global Historical Climatology Network (GHCN) daily rainfall data of NOAA (www.ncdc.noaa.gov/oa/climate/ghen-daily/) and the Ahn and Takeshi (1994) potential evapotranspiration data were used as input for each subbasin.

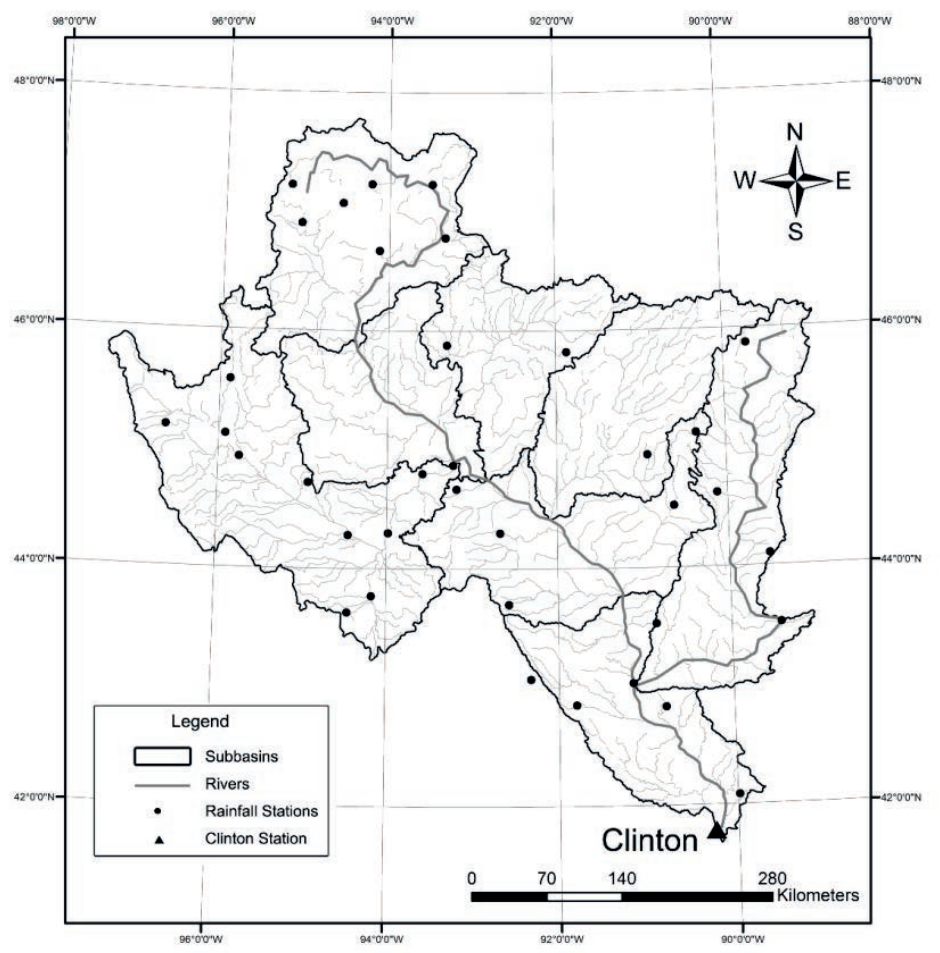

Fig. 1 The subbasins that were divided and the rainfall gauging stations.

Table 1 Parameters of the model being calibrated against satellite observations and the prior parameter ranges.

\begin{tabular}{llll}
\hline Name & Unit & Range & Description \\
\hline Cmax & $\mathrm{mm}$ & $1-400$ & Maximum storage capacity \\
Bexp & - & $0-2$ & Degree of spatial variability of the soil moisture capacity \\
Alpha & - & $0.2-0.99$ & Factor distributing the flow between slow and quick tanks \\
$K s$ & day & $0.01-0.5$ & Residence time of the slow release tank \\
$K q$ & day & $0.5-1.2$ & Residence time of the quick release tanks \\
$c$ & - & $10^{-5}-10^{-1}$ & Coefficient of the power relation in equation (2) \\
$f$ & - & $0.2-0.8$ & Exponent of the power relation in equation (2) \\
$H_{0}$ & $\mathrm{~m}$ & $165-175$ & Elevation of zero flow \\
\hline
\end{tabular}

\section{Calibration and uncertainty analysis}

The generalized likelihood uncertainty analysis (GLUE) proposed by Beven and Binley (1992) is used for model calibration. For the case study, the parameter needing calibration include the five 
parameters of HYMOD and the three parameters in equation (2). Using a Latin-Hypercube sampling algorithm, 100000 parameter sets were randomly selected based on the parameter ranges listed in Table 1 and the assumed uniform distribution. Then the generated parameter sets were applied to the integrated model (HYMOD + equation 2) to simulate water stage at Clinton for the period 1998-2002. To assess the performance of each parameter set, the likelihood measure was defined as the reciprocal of the relative mean square error (RMSE).

\section{RESULTS AND DISCUSSION}

The likelihood measure is an indicator for assessing each set of parameter values based on the observations at hand. Through several trial-and-error tests, the value of 1.333 (corresponding RMSE: $0.75 \mathrm{~m}$ ) was selected as the threshold of the likelihood. Among the 100000 randomly generated parameter sets, only 934 sets of parameters could be identified as behavioural simulators. Streamflow estimation was carried out by applying values of the five rainfall-runoff parameters in the 934 behavioural sets to HYMOD. The likelihood weighted uncertainty bounds of simulated streamflow were drawn, as shown in Fig. 2. The performance was satisfactory. The Nash-Sutcliffe efficiency of averaged streamflow simulated by the parameter sets is $64.50 \%$. The uncertainty band embraces about $65 \%$ of daily streamflow records of the five year period and captures the structure of streamflow variation reasonably.

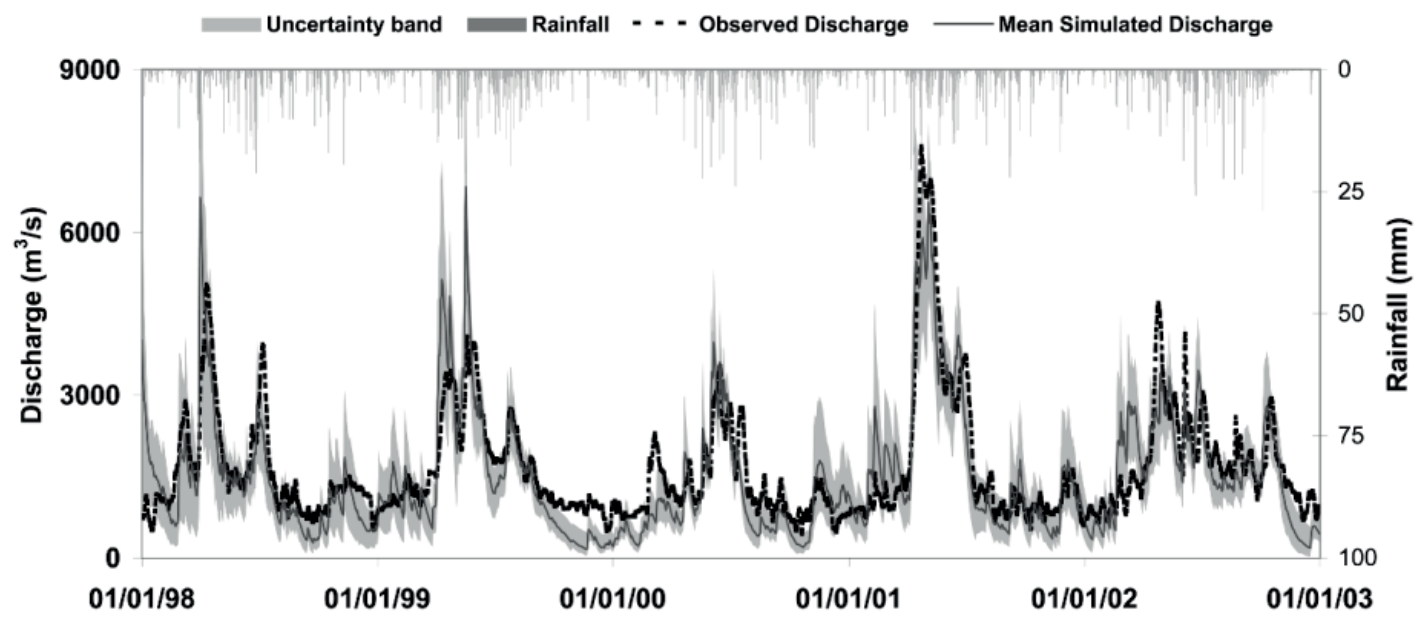

Fig. 2 The simulated streamflow with the $90 \%$ uncertainty limits by the behavioural parameter sets derived from the calibration against $\mathrm{T} / \mathrm{P}$ observations.

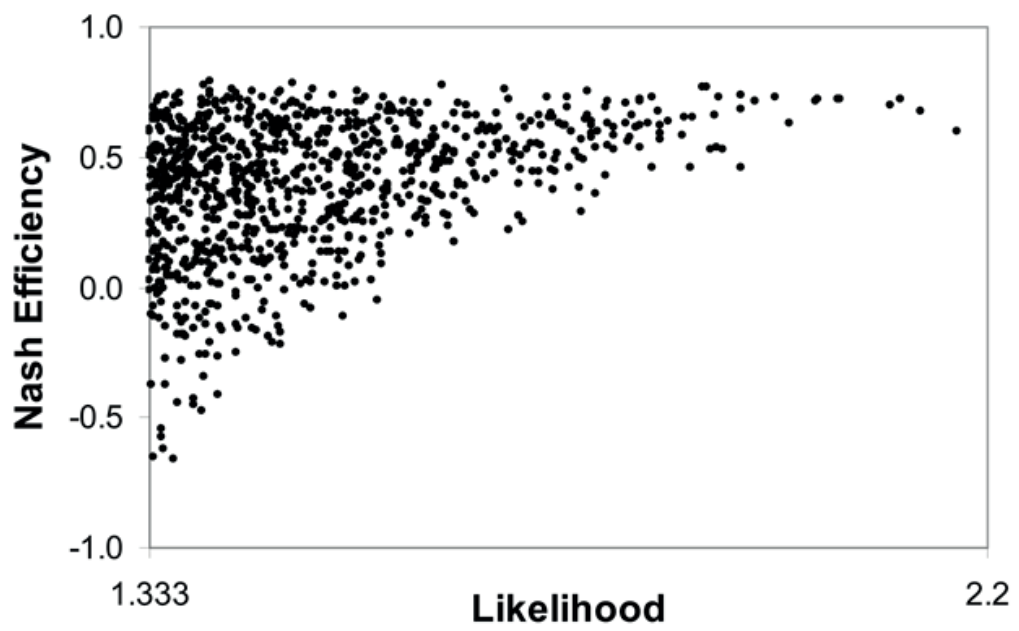

Fig. 3 Scatter plots of likelihoods versus Nash-Sutcliffe efficiencies for the behavioural parameter sets. 
Furthermore, the parameter response surface constrained on T/P observations is demonstrated by the plots of the likelihood value versus the Nash-Sutcliffe efficiency of simulated streamflow (Fig. 3). Similar to the results in Sun et al. (2010), the performance of streamflow simulation varies among the plots with the same likelihood value, reflecting the fact that satellite observations impose fewer constraints on the parameter space. Despite this, extrapolating the weight of each behavioural parameter set in the ensemble streamflow estimation from its likelihood can be considered as effective, because for the parameter sets having the same likelihood value, the dispersion decreases and the average performance increases, when moving along the likelihood axis direction.

These results indicate that the calibration using satellite observations is successful. However, the comparison with the calibration using streamflow observations is desired to make a complete evaluation of the proposed method. For the calibration based on continuous streamflow data, judging from the likelihood measure (the Nash-Sutcliffe efficiency), the top 934 parameter sets (keep the same number as for calibration using satellite observations) were treated as behavioural ones for making ensemble streamflow estimations. The uncertainty bounds of simulated streamflow are shown together with the averaged estimates at each step in Fig. 4. The NashSutcliffe efficiency of the mean simulation is $79.05 \%$. The uncertainty band is narrower than calibration based on satellite observations, indicating that the variability among the identified parameter sets in reproducing streamflow are lower. It is emphasized that the proposed method does not aim at replacing streamflow data in the process of model calibration; it is only valuable in the situation where streamflow data are unavailable.

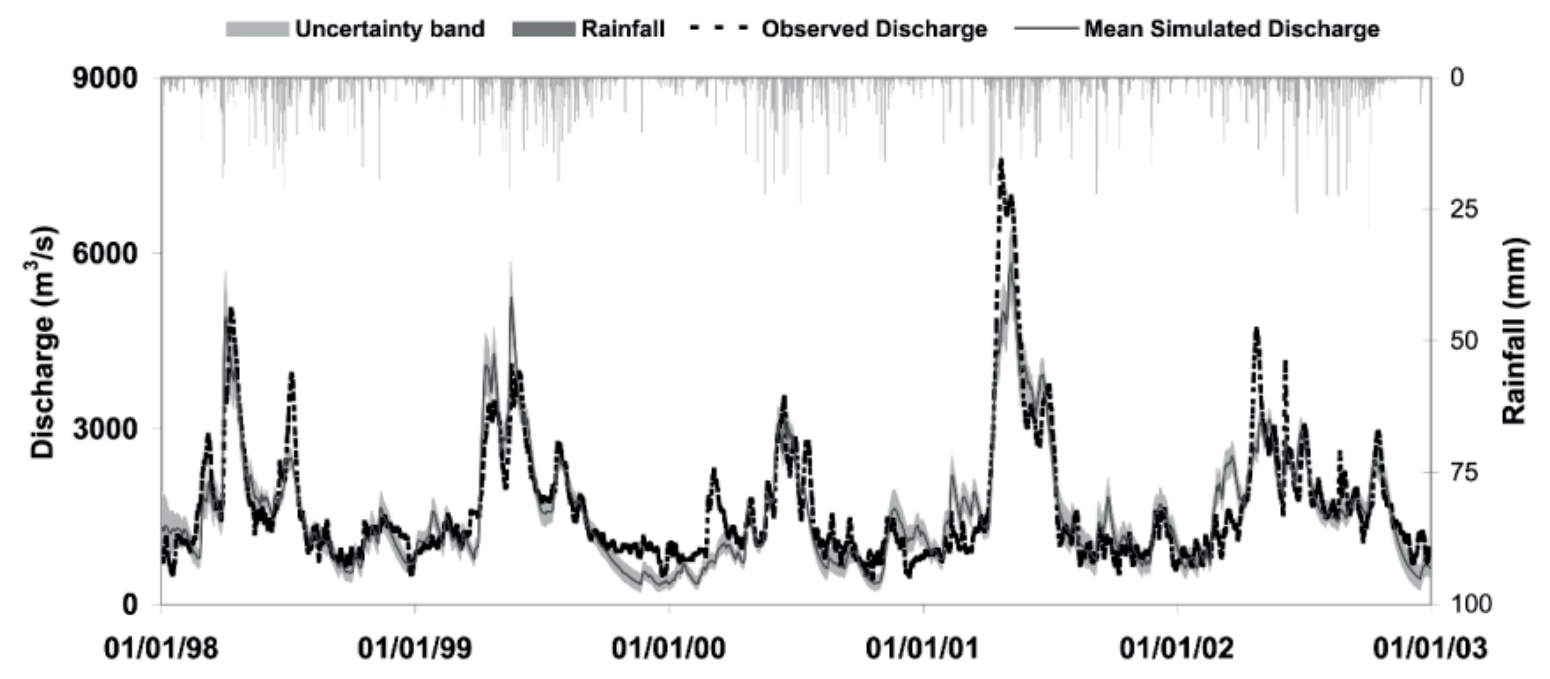

Fig. 4 The simulated streamflow with the $90 \%$ uncertainty limits by the behavioural parameter sets derived from the calibration against streamflow data.

\section{CONCLUSION}

This study is the first attempt at using water surface elevation data obtained from satellite radar altimeters as a surrogate of commonly used in situ streamflow observations in the process of the hydrological model calibration. The results show that the model was well calibrated using remote sensing data, indicating that this approach could be a new direction for solving the calibration problem of rainfall-runoff models in ungauged basins. Comparison with calibration using streamflow data shows that for the new calibration method, the uncertainty in the modelling process is higher and the parameter space is less constrained. It is in accordance with our understanding that potential of the radar altimetric data in this context only exists for the cases where streamflow data are unavailable. 
Acknowledgements The authors sincerely acknowledge the Ministry of Education, Culture, Sports, Science and Technology of Japan Grand-in-aid Scientific Research (No. 21560537, PI: Hiroshi Ishidaira, University of Yamanashi) for supporting this study. This study was also supported by the National Key Technology R\&D Program of China (Grant No. 2013BAB05B04) and the Fundamental Research Funds for the Central Universities of China. The authors would like to thank Mr Kris Lund, USGS Iowa Water Science Centre, for providing the information about the Clinton gauging station.

\section{REFERENCES}

Ahn, C. H. and Tateishi, R. (1994) Development of a global 30-minute grid potential evapotranspiration data set. Journal of the Japan Society of Photogrammetry and Remote Sensing 33(2), 12-21.

Benke, A. C. and Cushing, C. E. (2005) River of North America. New York: Academic Press, 329.

Beven, K. J. (2001) How far can we go in distributed hydrological modelling? Hydrology and Earth System Science 5(1), 1-12.

Beven, K. J. and Binley, A. (1992) The future of distributed models: Model calibration and uncertainty prediction. Hydrological Processes 6(3), 279-298.

Boyle, D. P., 2000. Multicriteria calibration of hydrological models. PhD. Thesis, University of Arizona, Tucson, AZ, USA.

Leopold, L. B. and Maddock, T. (1953) The hydraulic geometry of stream channels and some physiographic implications. US Geological Survey Professional Paper 252.

Moore, R. J. (1985) The probability-distributed principle and runoff production at point and basin scales. Hydrological Science Journal 30(2), 273-297.

Ranz, S. E. et al. (1982) Measurement and computation of streamflow: Volume 2. Computation of discharge. USGS Geological Survey Water-Supply Paper 2175, 285-361.

Schumann, G., et al. (2009) Progress in integration of remote sensing-derived flood extent and stage data and hydraulic models. Reviews of Geophysics 47, RG4001, doi: 10.1029/2008RG000274.

Sivapalan, M., et al. (2003) IAHS decade on predictions in ungauged basins (PUB), 2003-2012: shaping an exciting future for the hydrological sciences. Hydrological Sciences Journal 48(6), 857-880.

Smith, L. C. (1997) Satellite remote sensing of river inundation area, stage, and discharge: a review. Hydrological Processes $11,1427-1439$.

Sun, W, Ishidaira, H. and Bastola, S. (2010) Towards improving river discharge estimation in ungauged basins: calibration of rainfall-runoff models based on satellite observations of river flow width at basin outlet. Hydrology and Earth System Science 14, 2011-2022, doi: 10.5194/hess-14-2011-2010. 